\title{
Preparation of Nanofibrous Metal-Organic Framework Filters for Efficient Air Pollution Control
}

\author{
Supporting Information
}

Yuanyuan Zhang, Shuai Yuan, Xiao Feng, Haiwei Li, Junwen Zhou, Bo Wang*

\section{Contents}

Section A. Materials and methods

Section B. Experimental section

Section C. Supplementary spectra (Figure S2-S18)

Section D. Supporting references 


\section{Section A. Materials and methods}

All chemicals and solvents were obtained from commercial suppliers including Alfa Aesar, Sigma-Aldrich and Beijing Chemical Reagent Company, and used without further purification.

Powder X-ray diffraction (PXRD) patterns were recorded on a Bruker Focus D8 diffractometer with $\mathrm{Cu}-\mathrm{K} \alpha \mathrm{X}$-ray radiation $(\lambda=0.154056 \mathrm{~nm})$.

Field-emission scanning electron microscopy (FE-SEM) images were acquired from a JEOL model S-4800 scanning electron microscope. Prior to observation the filters were sputter-coated with platinum layers to increase their conductivity.

Transmission electron microscopy (TEM) was carried out by a JEOL JEM-1200EX Transmission electron microscope.

$\mathrm{N}_{2}$ sorption isotherms were measured at $77 \mathrm{~K}$ on a Quantachrome Instrument ASiQMVH002-5 after pretreatment.

$\zeta$ potentials were measured on a Malvern Zetasizer Nano ZS90. The MOF powders were dispersed in ethanol and sonicated for several minutes before measured.

Analysis of the effluent gas from the sample was carried out by using a Hiden Analytical HPR-20 mass spectrometer.

Measurement of the mass concentration of the particle matter was conducted on a CEM DT-9880M/9881M particle counter.

Processing of the filters was performed on a UCALERY SS-2534H electrospinning setup. 


\section{Section B. Experimental section}

\section{Preparation of MOFs}

Synthesis of UiO-66- $\mathrm{NH}_{2}{ }^{1}: \mathrm{ZrCl}_{4}$ (pre-dissolved in a $\mathrm{DMF} / \mathrm{HCl}$ mixture of $\mathrm{v}(\mathrm{DMF}): \mathrm{v}(\mathrm{HCl})=5: 1)$ and 2-amino-4,4'-dicarboxylic acid (pre-dissolved in DMF) at a molar ratio of 1:1.4 were mixed and heated at $80{ }^{\circ} \mathrm{C}$ overnight. The obtained powders were isolated by centrifugation and washed with DMF $(3 \times 30 \mathrm{~mL})$. Then the powders were immersed in ethanol for 3 days (the solvent was replaced with fresh ethanol each day). Finally, the product was dried under vacuum at $150{ }^{\circ} \mathrm{C}$ overnight.

Synthesis of $\mathrm{ZIF}-8^{2}: 1.291 \mathrm{~g}$ of $\mathrm{Zn}\left(\mathrm{NO}_{3}\right)_{2} \cdot 4 \mathrm{H}_{2} \mathrm{O}$ was dissolved in $100 \mathrm{~mL}$ of methanol, and $1.621 \mathrm{~g}$ of 2-methylimidazole was dissolved in $100 \mathrm{~mL}$ of methanol. Then the two solutions were mixed under stirring and kept statically at room temperature for $24 \mathrm{~h}$. The resultant powders were collected by centrifugation and thoroughly washed with methanol. The product was dried at $120{ }^{\circ} \mathrm{C}$ for $12 \mathrm{~h}$ in a vacuum oven.

Synthesis of Mg-MOF-74³ $: 0.337 \mathrm{~g}$ of 2,5-dihydroxyterephthalic acid and $1.4 \mathrm{~g}$ of $\mathrm{Mg}\left(\mathrm{NO}_{3}\right)_{2} \cdot 6 \mathrm{H}_{2} \mathrm{O}$ were dissolved in a solution of $135 \mathrm{~mL}$ of DMF, $9 \mathrm{~mL}$ of ethanol, and $9 \mathrm{~mL}$ of water. The mixture was heated at $125^{\circ} \mathrm{C}$ for $26 \mathrm{~h}$ and the obtained powder was washed with DMF and methanol. The product was immersed in methanol for 4 days before drying at $120^{\circ} \mathrm{C}$ for $12 \mathrm{~h}$ under vacuum.

Synthesis of MOF-199 ${ }^{4}: 0.126 \mathrm{~g}$ of 1,3,5-benzenetricarboxylic acid was dissolved in 2 $\mathrm{mL}$ of DMF with $0.25 \mathrm{~mL}$ of triethylamine, and $0.215 \mathrm{~g}$ of $\mathrm{Cu}(\mathrm{OAc})_{2} \cdot \mathrm{H}_{2} \mathrm{O}$ was dissolved in 5 $\mathrm{mL}$ of DMF. The two solutions were combined in a mixture solution of DMF (18 $\mathrm{mL})$, ethanol $(25 \mathrm{~mL})$ and $\mathrm{H}_{2} \mathrm{O}(25 \mathrm{~mL})$ and stirred vigorously for an hour at room temperature. 
The resultant powder was washed with DMF for 3 times and then immersed in ethanol for 24 $\mathrm{h}$ before drying at $120^{\circ} \mathrm{C}$ under vacuum.

\section{Preparation of electrospinning solutions}

PAN solution: $0.32 \mathrm{~g}$ of PAN $\left(M_{\mathrm{w}}=150,000\right)$ was added in $3 \mathrm{~mL}$ of DMF and the solution was stirred overnight to form a homogeneous solution with a concentration of 10 wt $\%$. The PAN solutions of different concentrations (6 wt \% and 8 wt $\%)$ were prepared in the same way.

PS solution: $0.54 \mathrm{~g}$ of PS $\left(M_{\mathrm{w}}=280,000\right)$ was added in $3 \mathrm{~mL}$ of DMF and the solution was stirred overnight to form a homogeneous solution with a concentration of $16 \mathrm{wt} \%$.

PVP solution: $0.5 \mathrm{~g}$ of $\operatorname{PVP}\left(M_{\mathrm{w}}=1.3 \times 10^{6}\right)$ was added in $8.45 \mathrm{~mL}$ of ethanol and the solution was stirred overnight to form a homogeneous solution with a concentration of 7 wt $\%$.

MOF/PAN solution: $0.08 \mathrm{~g}$ of MOF powder was first dispersed in $3 \mathrm{~mL}$ of DMF by sonicating and then $0.12 \mathrm{~g}$ of PAN was added, and the mixture was stirred for $3 \mathrm{~h}$. Then the rest $0.20 \mathrm{~g}$ of PAN was added and dissolved forming a homogeneously dispersed MOF/PAN solution with a MOF loading of $20 \mathrm{wt} \%$. The MOF/PAN solutions of different MOF loadings ranging from $20 \mathrm{wt} \%$ to $60 \mathrm{wt} \%$ were prepared by varying the amount of MOF added.

$\mathrm{MOF} / \mathrm{PS}$ and MOF/PVP solution were prepared in the same way.

\section{Preparation of MOFilters}

Preparation of PAN filter: The PAN/DMF solution (10 wt \%) was transferred to the electrospinning setup and spun at a flow rate of $1 \mathrm{~mL} / \mathrm{h}$ with a spinneret of $0.6 \mathrm{~mm}$ in diameter. A high voltage of $10 \mathrm{kV}$ was applied and the distance between the collector and the 
spinneret was set at $20 \mathrm{~cm}$. The thus obtained fibers were collected on various substrates (aluminum foil, nonwoven fabric or stainless steel mesh). The electric voltage was adjusted $(8-12 \mathrm{kV})$ for solutions with different concentrations. The temperature and relative humidity were kept at $25^{\circ} \mathrm{C}$ and $35 \%$.

Preparation of PAN-MOFilters (20 wt \% MOF loading): The MOF/PAN solution was electrospun onto substrates (aluminum foil, nonwoven fabric or stainless steel mesh) at the voltage of $12 \mathrm{kV}$. The flow rate was $1 \mathrm{~mL} / \mathrm{h}$ and the spinneret diameter was $0.6 \mathrm{~mm}$. The distance between the collector and the spinneret was set at $20 \mathrm{~cm}$. For the preparation of MOFilters for PM capture, the spinneret was shifted at a rate of $200 \mathrm{~mm} / \mathrm{min}$ with a span of $40 \mathrm{~mm}$ to collect a uniform layer onto the nonwoven support, and the electrospnning time was $5 \mathrm{~min}$. The thickness of the nonwoven support and the filter with the support is $28 \mu \mathrm{m}$ and 33 $\mu \mathrm{m}$, respectively.

Preparation of PAN-MOFilters (60 wt \% MOF loading): The MOF/PAN solution was electrospun onto substrates (aluminum foil, nonwoven fabric or stainless steel mesh) at 10-12 $\mathrm{kV}$. The flow rate was $0.8-1 \mathrm{~mL} / \mathrm{h}$ and the spinneret diameter was $0.6 \mathrm{~mm}$. The distance between the collector and the spinneret was set at $20 \mathrm{~cm}$. The temperature and relative humidity were kept at $25{ }^{\circ} \mathrm{C}$ and $35 \%$. Due to the different properties of MOFs, the voltage and flow rate were adjusted a little. ZIF-8 $(12 \mathrm{kV}, 1 \mathrm{~mL} / \mathrm{h}), \mathrm{UiO}-66-\mathrm{NH}_{2}(12 \mathrm{kV}, 0.8 \mathrm{~mL} / \mathrm{h})$, MOF-199 (10 kV, $0.8 \mathrm{~mL} / \mathrm{h})$ and Mg-MOF-74 (12 kV, $0.8 \mathrm{~mL} / \mathrm{h})$. For the preparation of MOFilter for $\mathrm{SO}_{2}$ adsorption, the spinneret was shifted at a rate of $200 \mathrm{~mm} / \mathrm{min}$ with a span of $40 \mathrm{~mm}$ to collect a uniform layer onto the nonwoven support, and the electrospnning time was $60 \mathrm{~min}$. The thickness of the nonwoven support and the filter with the support is $28 \mu \mathrm{m}$ and 
$40 \mu \mathrm{m}$, respectively. The MOFilters were immersed in ethanol for $12 \mathrm{~h}$ for solvent exchange and dried at $120^{\circ} \mathrm{C}$ for $12 \mathrm{~h}$ in a vacuum oven.

Preparation of PS filter: The PS/DMF solution (16 wt \%) was electrospun onto substrates (aluminum foil, nonwoven fabric or stainless steel mesh) at $12 \mathrm{kV}$. The feed rate was $1 \mathrm{~mL} / \mathrm{h}$ and the spinneret diameter was $0.6 \mathrm{~mm}$. The distance between the collector and the spinneret was set at $20 \mathrm{~cm}$. The temperature and relative humidity were kept at $25^{\circ} \mathrm{C}$ and $35 \%$.

Preparation of PS-MOFilters (60 wt \% MOF loading): The MOF/PS solution was electrospun onto substrates (aluminum foil, nonwoven fabric or stainless steel mesh) at 12-14 $\mathrm{kV}$. The flow rate was $0.8-1 \mathrm{~mL} / \mathrm{h}$ and the spinneret diameter was $0.6 \mathrm{~mm}$. The distance between the collector and the spinneret was set at $20 \mathrm{~cm}$. The temperature and relative humidity were kept at $25^{\circ} \mathrm{C}$ and $35 \%$. Due to the different properties of MOFs, the voltage and flow rate were adjusted a little. ZIF-8 $(14 \mathrm{kV}, 0.8 \mathrm{~mL} / \mathrm{h}), \mathrm{UiO}-66-\mathrm{NH}_{2}(14 \mathrm{kV}, 1 \mathrm{~mL} / \mathrm{h})$, MOF-199 (12 kV, $0.8 \mathrm{~mL} / \mathrm{h})$ and Mg-MOF-74 (12 kV, $0.8 \mathrm{~mL} / \mathrm{h})$.

The PVP filter and PVP-MOFilters were fabricated in the similar method with electrospinning parameters: electric voltage $(10-14 \mathrm{kV})$, flow rate $(0.8-1 \mathrm{~mL} / \mathrm{h})$, spinneret diameter $(0.6 \mathrm{~mm})$ and distance $(20 \mathrm{~cm})$.

\section{Particulate matter removal experiment}

The PM removal efficiency of the filters was tested in the setup shown in Figure S1, and the setup was put in a heavily polluted environment during the test. A piece of filter with a diameter of $4 \mathrm{~cm}$ was set at one side of the pipe, and an electric fan is put on the other side to help the air pass through the filter at a constant velocity. The filtered air was collected in a plastic bag, and a particle counter was used to detect the PM mass concentrations with and 
without the filter. The detection was finished before the plastic bag reached its maximum volume, and this constant pressure process ensured that the concentration of PM remained unchanged during collection. The PM removal efficiency of the MOFilters was calculated with the following equations:

$$
\text { Efficiency }=\frac{C_{0}-C}{C_{0}}
$$

where $C_{0}\left(\mu \mathrm{g} / \mathrm{m}^{3}\right)$ and $C\left(\mu \mathrm{g} / \mathrm{m}^{3}\right)$ are the mass concentrations of particle matter with and without the filter.

The long-term PM removal efficiency of the filter is tested every 4 hours for 2 days. The filters were weighed before and after PM filtration to get the mass change that indicates the amount of the particles captured on the filters. The gravimetric mass change $\left(\Delta \mathrm{m}_{\mathrm{G}}\right)$ and the areal mass change $\left(\Delta m_{\mathrm{A}}\right)$ of the filters was calculated with the following equations:

$$
\begin{aligned}
\Delta m_{G} & =\frac{m-m_{0}}{m_{0}} \\
\Delta m_{A} & =\frac{m-m_{0}}{S}
\end{aligned}
$$

where $m(\mathrm{~g})$ and $m_{0}(\mathrm{~g})$ are the mass of the filter before and after PM filtration (the mass of the substrate was included); $\mathrm{S}\left(\mathrm{m}^{2}\right)$ is the area of the filter.

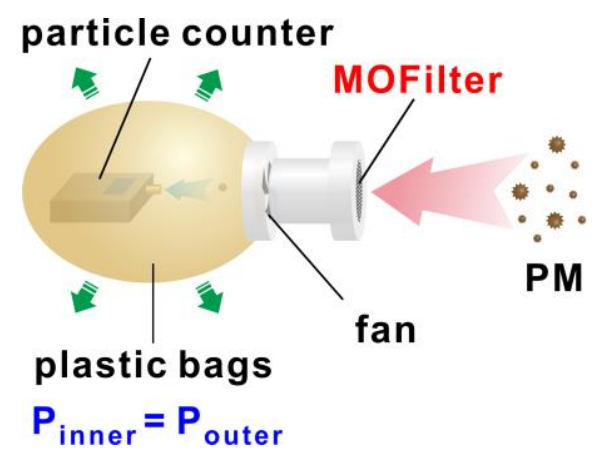

Figure S1. Setup for particulate matter filtration test. 


\section{$\mathrm{SO}_{2}$ dynamic adsorption experiment}

The dynamic adsorption test was conducted in the homemade apparatus shown in Figure S9. The $\mathrm{SO}_{2}$ and $\mathrm{N}_{2}$ flow were mixed reaching a concentration of $100 \mathrm{ppm}$ and downstream concentration of the mixed gas was recorded using a mass spectrometer. The mixture was first passed through the blank cell at the rate of $50 \mathrm{~mL} / \mathrm{min}$; once the downstream concentration reached $100 \mathrm{ppm}$ and remained unchanged in $20 \mathrm{~min}$, the valve of the blank cell was shut and valve of the filter cell was open. Eight layers of the filter with a diameter of $2 \mathrm{~cm}$ was set in the filter cell and exposed to the stream. Dynamic adsorption capacities $(\mathrm{g} / \mathrm{g})$ of the filters were calculated with the following equations:

$$
\begin{gathered}
m_{\text {feed }}=C_{\text {feed }} \cdot r_{\text {feed }} \cdot t \\
m_{\text {out }}=\int_{0}^{t} C_{\text {out }} \cdot r_{\text {feed }} d t \\
\text { Capacity }=\frac{m_{\text {feed }}-m_{\text {out }}}{m_{0}}
\end{gathered}
$$

where $C_{\text {feed }}(\mathrm{g} / \mathrm{mL})$ and $C_{\text {out }}(\mathrm{g} / \mathrm{mL})$ are the concentration of the $\mathrm{SO}_{2} / \mathrm{N}_{2}$ mixture before and after adsorption; $r_{\text {feed }}(\mathrm{mL} / \mathrm{min})$ is the flow rate of the stream; $t(\mathrm{~min})$ is the time when the concentration of the downstream went back to the original concentration; $m_{\text {feed }}(\mathrm{g})$ and $m_{\text {out }}(\mathrm{g})$ are the total mass of the $\mathrm{SO}_{2}$ in the feed flow and downstream during the adsorption process; $\mathrm{m}_{0}$ is the mass of the filter (the mass of the substrate is not included). 


\section{Section C. Supplementary spectra (Figure S2-S18)}

a)

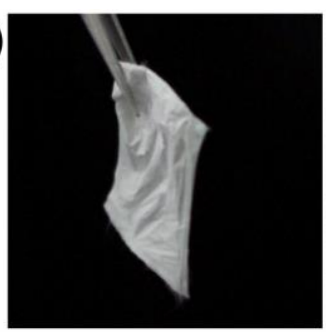

b)

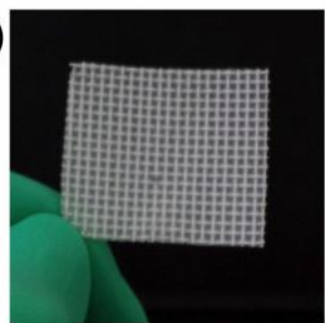

c)

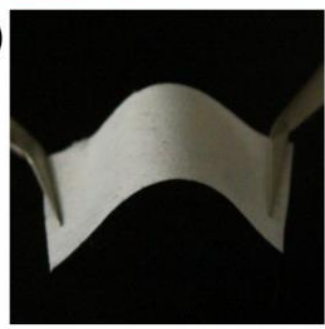

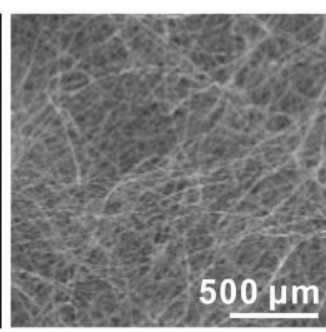
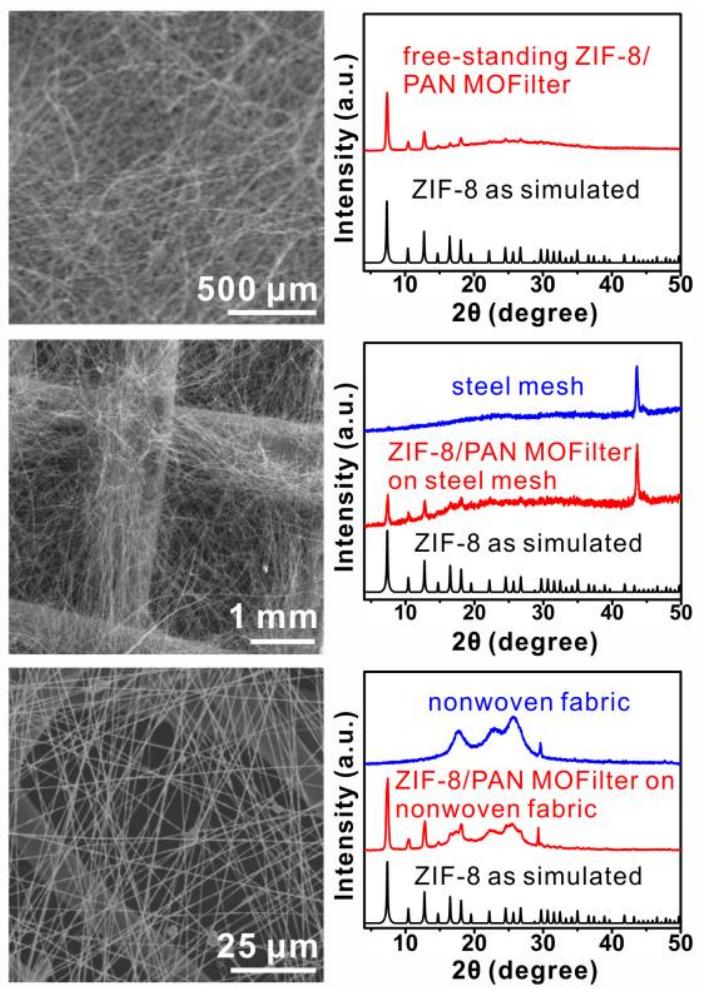

Figure S2. Optic photos, SEM images and PXRD patterns of (a) the free-standing ZIF-8/PAN MOFilter, (b) ZIF-8/PAN MOFilter supported on the stainless steel wire mesh and (c) ZIF-8/PAN MOFilter supported on the flexible nonwoven fabric. All the filters are loaded with 60 wt \% ZIF-8. 

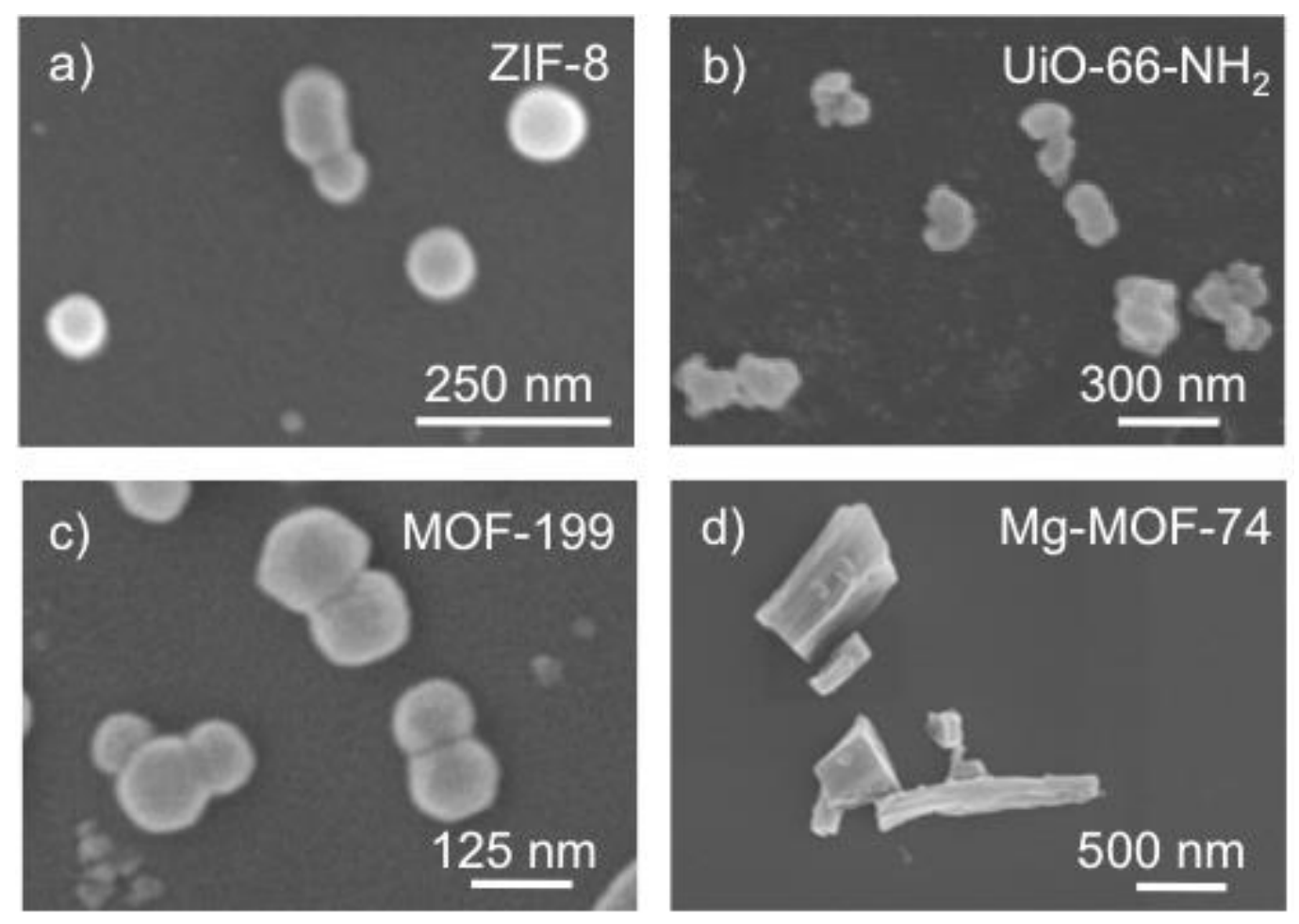

Figure S3. SEM images of MOF particles (a) ZIF-8, (b) UiO-66-NH $\mathrm{N}_{2}$, (c) MOF-199 and (d) Mg-MOF-74. 

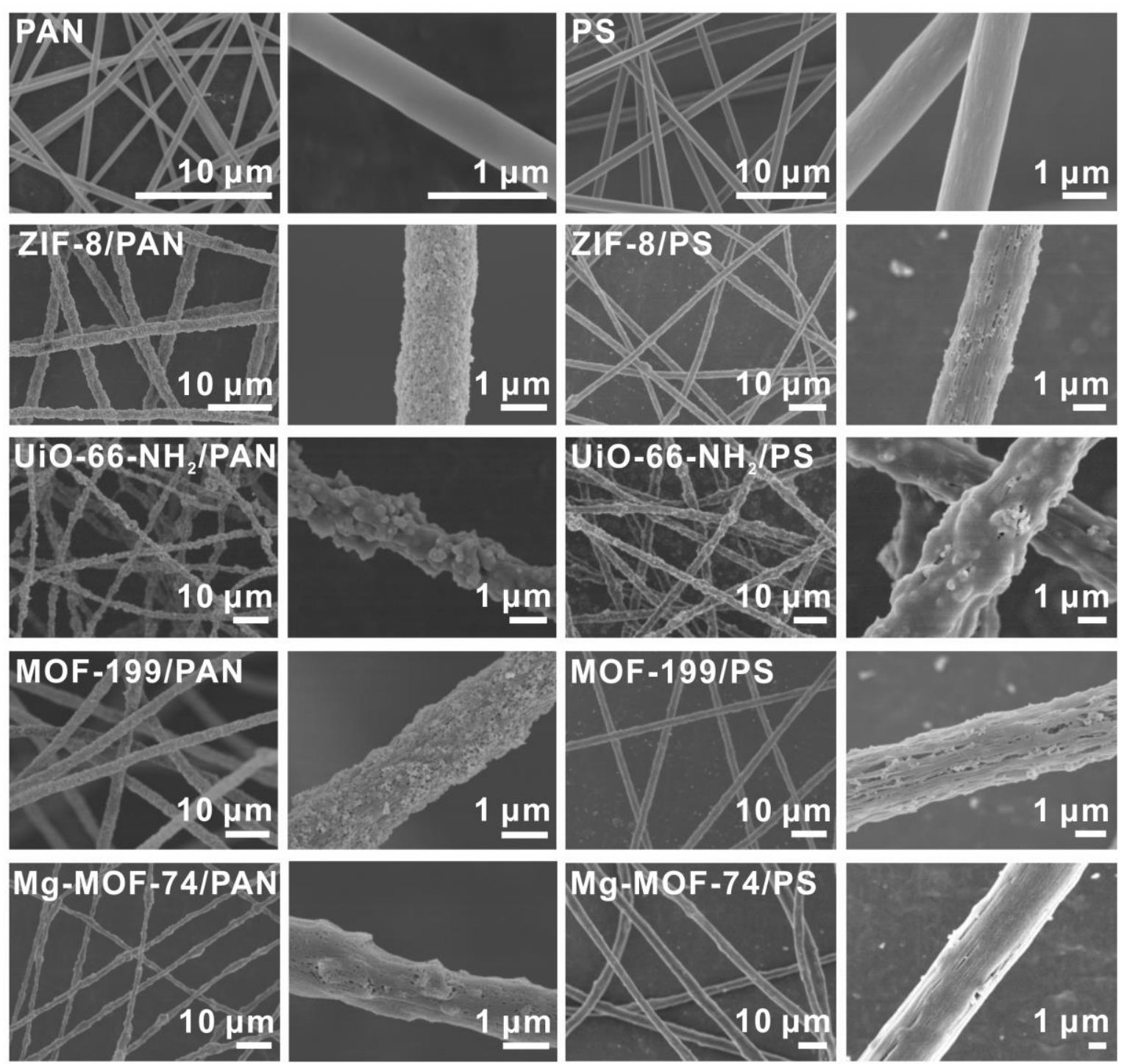

Figure S4. SEM images of PAN-MOFilters and PS-MOFilters supported on nonwoven fabrics. All the filters shown are loaded with $60 \mathrm{wt} \%$ corresponding MOF. 
a)

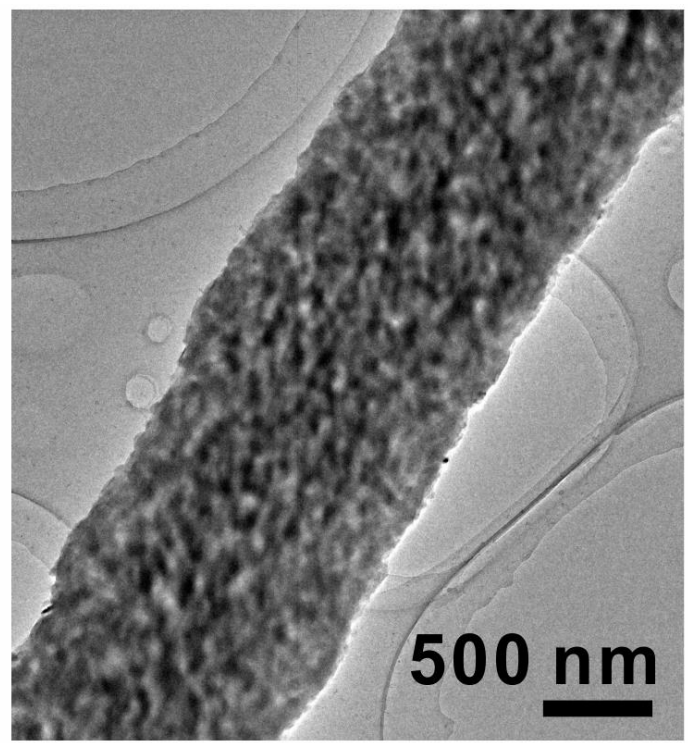

b)

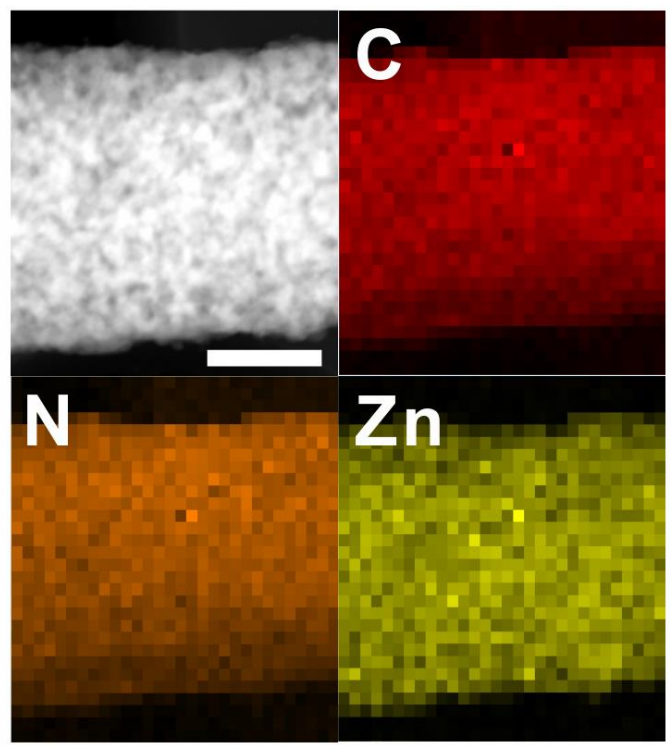

Figure S5. (a) TEM pattern and (b) EDS mapping images of ZIF-8/PAN composite fibers with a MOF loading of $60 \mathrm{wt} \%$. 

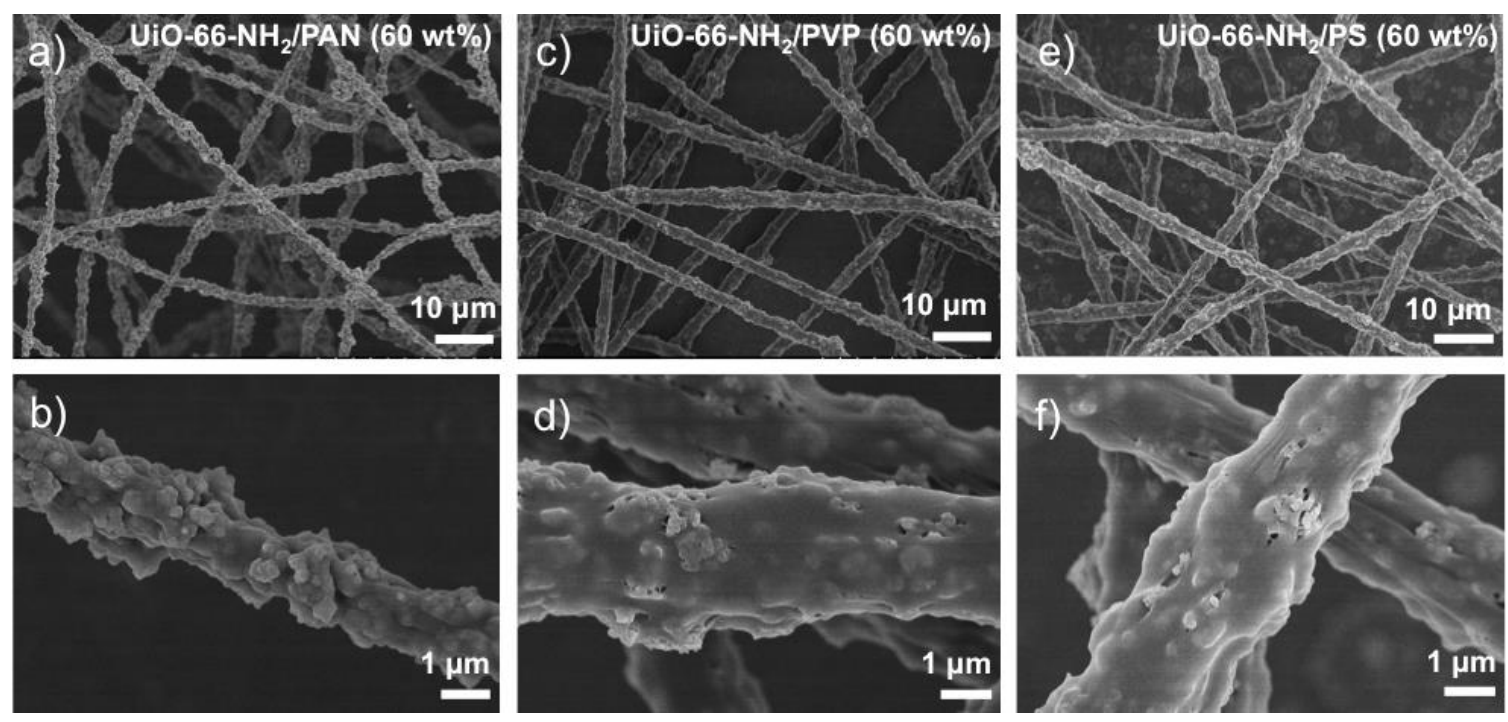

Figure S6. SEM images of (a, b) UiO-66- $\mathrm{NH}_{2} / \mathrm{PAN}$ MOFilter, (c, d) UiO-66-- $\mathrm{NH}_{2} / \mathrm{PVP}$ MOFilter and (e, f) UiO-66- $\mathrm{NH}_{2} / \mathrm{PS}$ MOFilter. All the filters are loaded with 60 wt $\%$ MOF. 

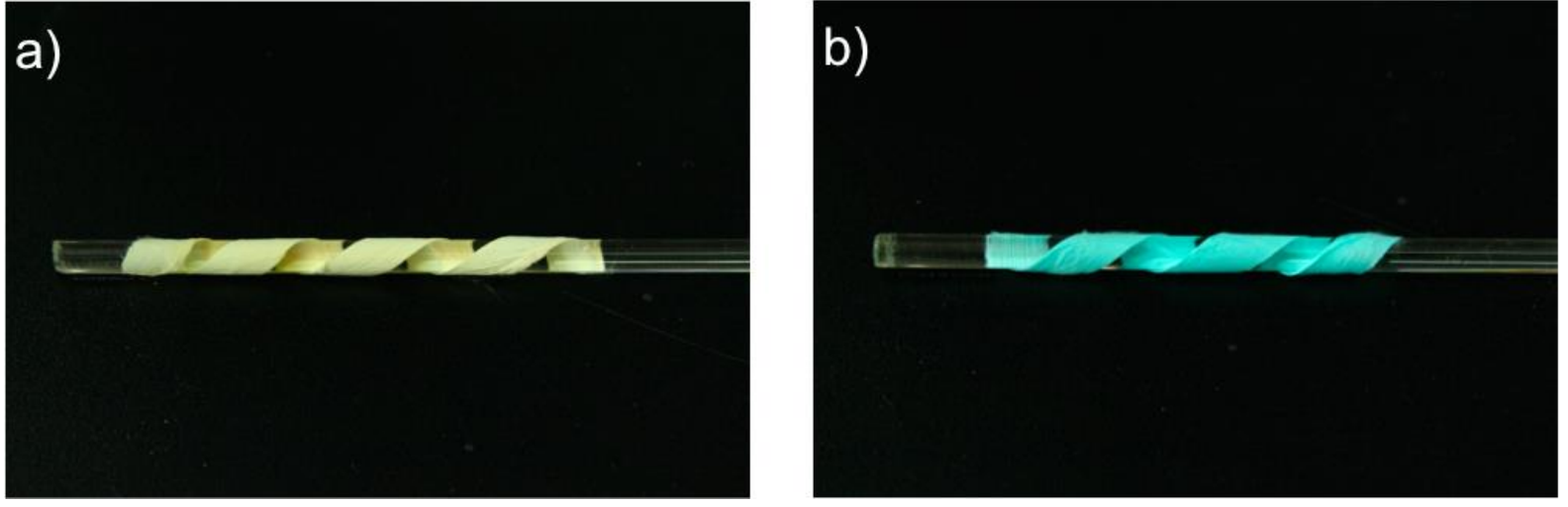

Figure S7. Photos of (a) free-standing UiO-66- $\mathrm{NH}_{2} / \mathrm{PAN}$ MOFilter, and (b) free-standing MOF-199/PS MOFilter with $60 \mathrm{wt} \%$ corresponding MOF twisted around the glass rods. 

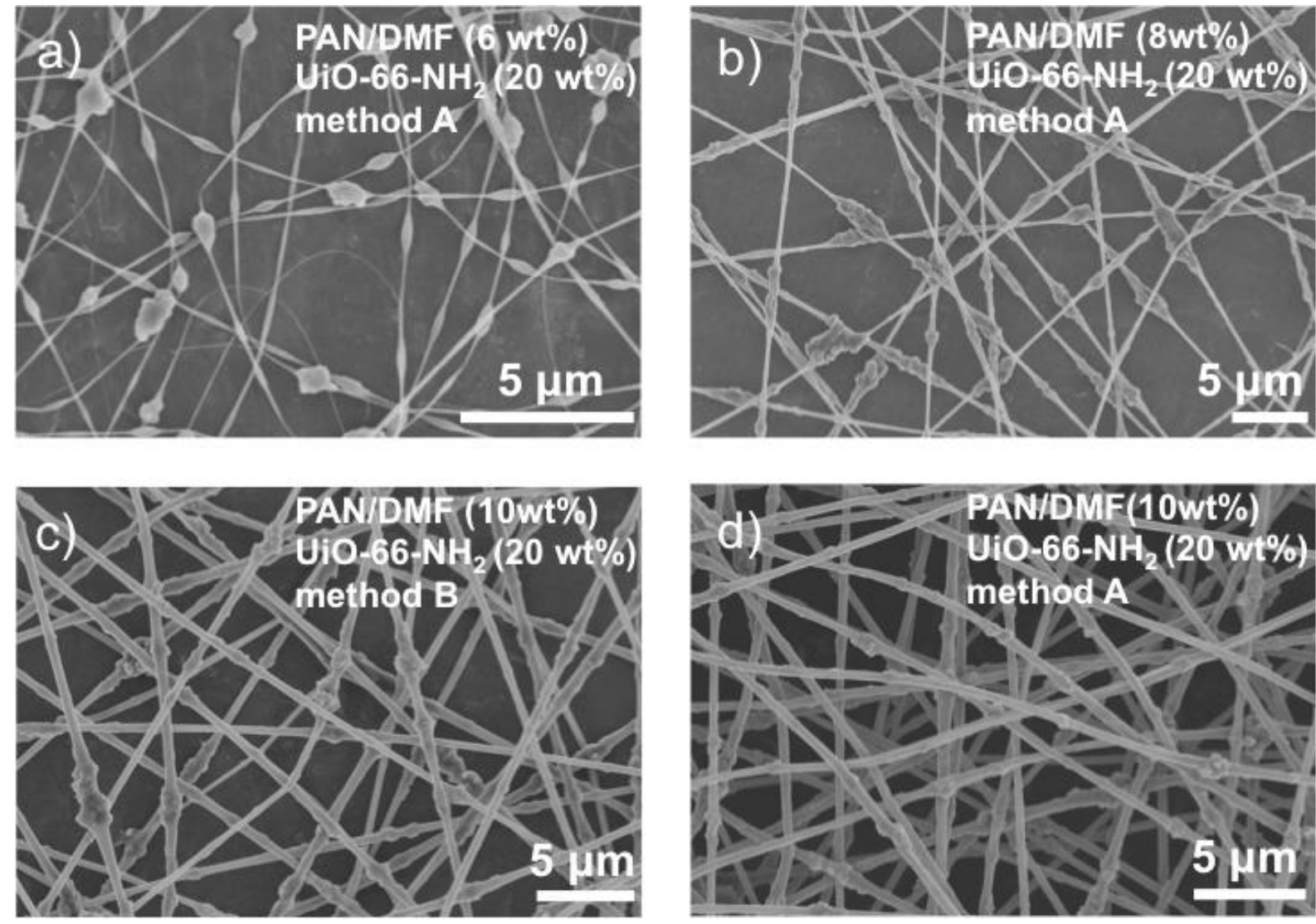

Figure S8. SEM image of the UiO-66- $\mathrm{NH}_{2} / \mathrm{PAN}$ MOFilter electrospun from PAN/DMF/UiO-66- $\mathrm{NH}_{2}$ solution with (a) PAN concentration of 6 wt $\%$, (b) PAN concentration of $8 \mathrm{wt} \%$ and (c, d) PAN concentration of $10 \mathrm{wt} \%$, a, b and d were prepared by priming technique (method A), and c was prepared by directly mixing the MOF and polymer in the solvent (method B) 

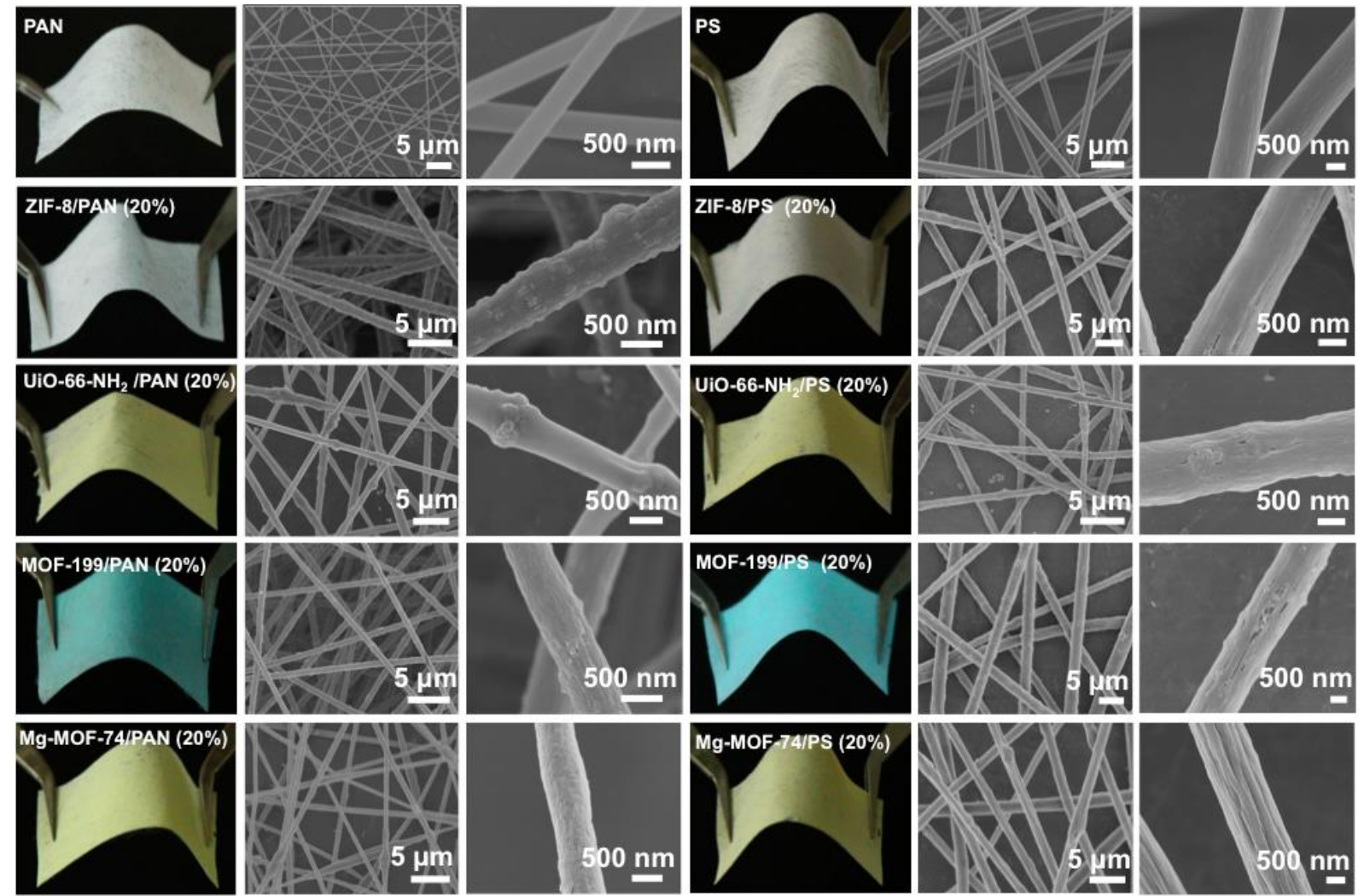

Figure S9. Photos and SEM images of PAN-MOFilters and PS-MOFilters supported on nonwoven fabrics. All the filters shown are loaded with 20 wt \% corresponding MOF. 

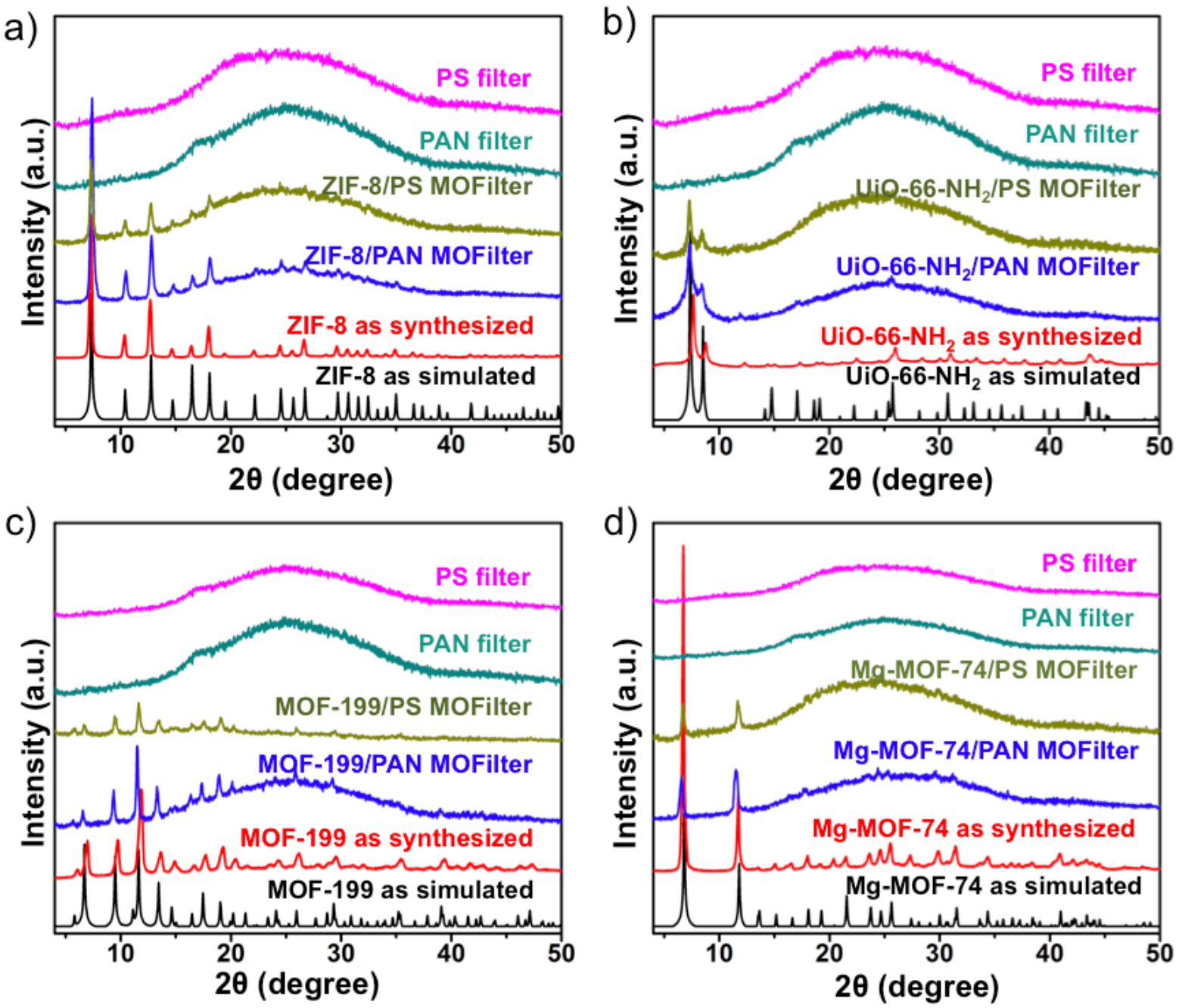

Figure S10. (a) PXRD patterns of ZIF-8, ZIF-8/PAN MOFilter, ZIF-8/PS MOFilter, PAN filter, PS filter and simulated PXRD pattern of ZIF-8. (b) PXRD patterns of UiO-66- $\mathrm{NH}_{2}$, UiO-66- $\mathrm{NH}_{2} / \mathrm{PAN}$ MOFilter, UiO-66- $\mathrm{NH}_{2} / \mathrm{PS}$ MOFilter, PAN filter, PS filter and simulated PXRD pattern of UiO-66-NH2. (c) PXRD patterns of MOF-199, MOF-199/PAN MOFilter, MOF-199/PS MOFilter, PAN filter, PS filter and simulated PXRD pattern of MOF-199. (d) PXRD patterns of Mg-MOF-74, Mg-MOF-74/PAN MOFilter, Mg-MOF-74/PS MOFilter, PAN filter, PS filter and simulated PXRD pattern of Mg-MOF-74. All the MOFilters are loaded with $60 \mathrm{wt} \%$ corresponding MOF and the filters were tested without substrate. 

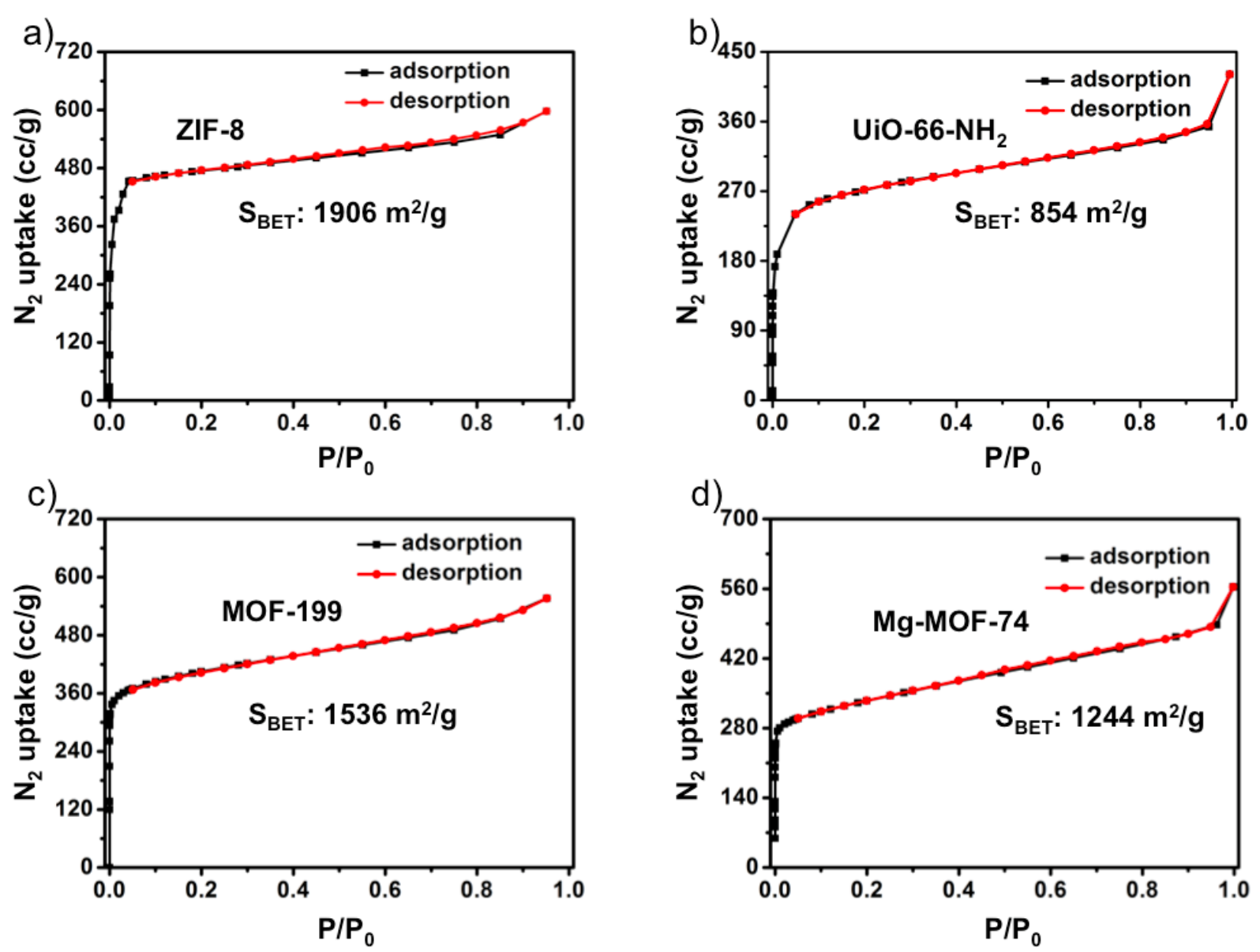

Figure S11. $\mathrm{N}_{2}$ sorption isotherms of (a) ZIF-8, (b) UiO-66-NH 2 , (c) MOF-199 and (d) Mg-MOF-74 measured at $77 \mathrm{~K}$. 

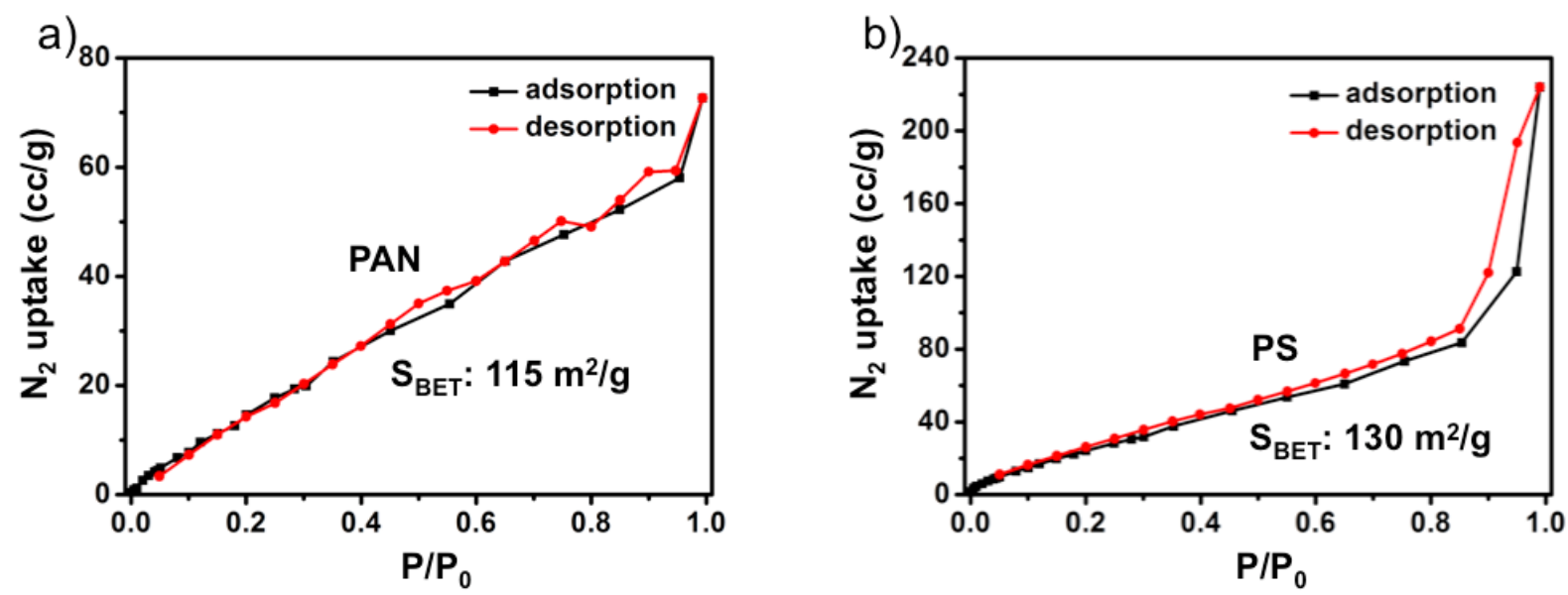

Figure S12. $\mathrm{N}_{2}$ sorption isotherms of polymer filters (a) PAN and (b) PS measured at $77 \mathrm{~K}$. 

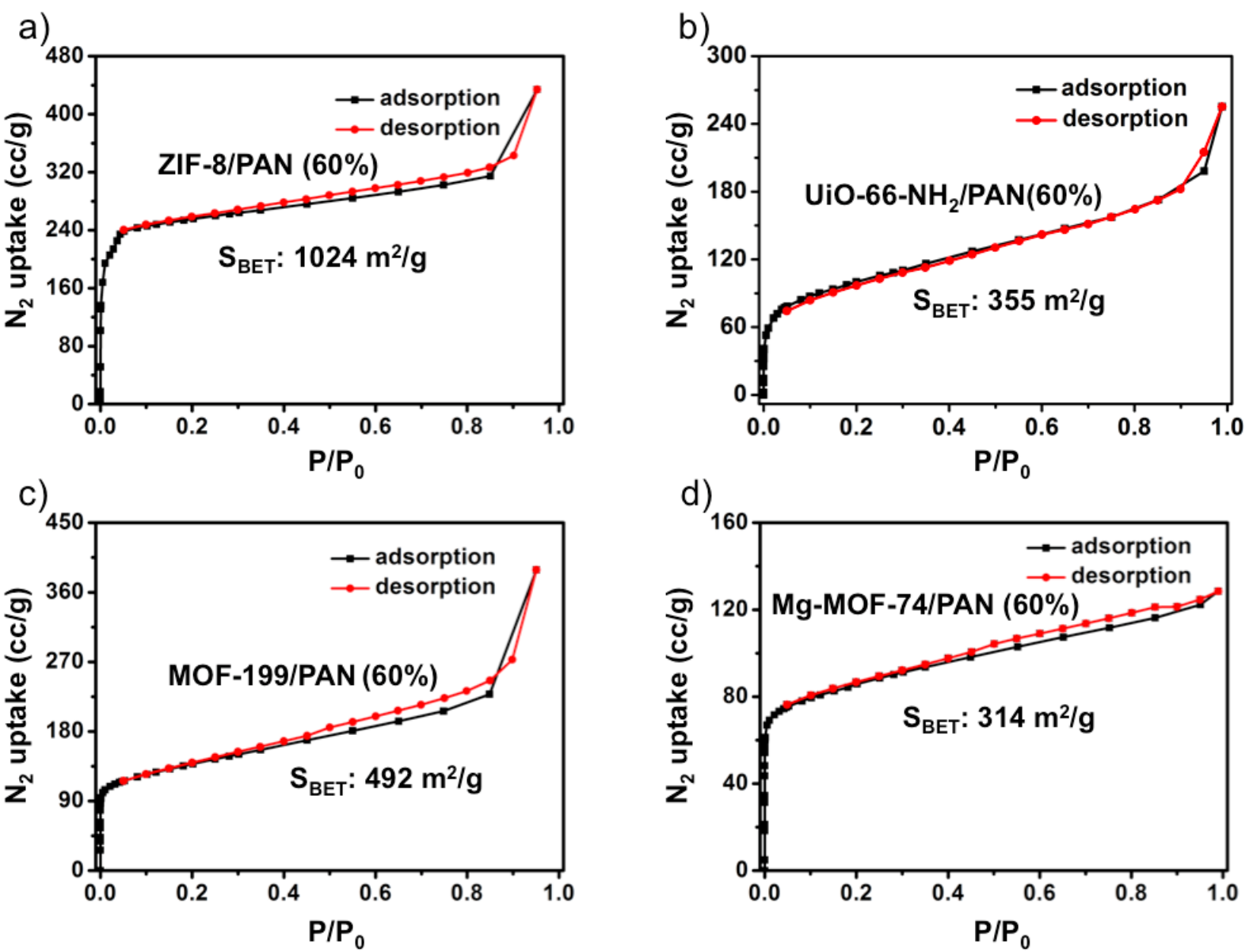

Figure S13. $\mathrm{N}_{2}$ sorption isotherms of PAN-MOFilters (a) ZIF-8/PAN, (b) UiO-66-NH $/ 2$ PAN, (c) MOF-199/PAN and (d) Mg-MOF-74/PAN with $60 \mathrm{wt} \%$ MOF loading measured at $77 \mathrm{~K}$. 

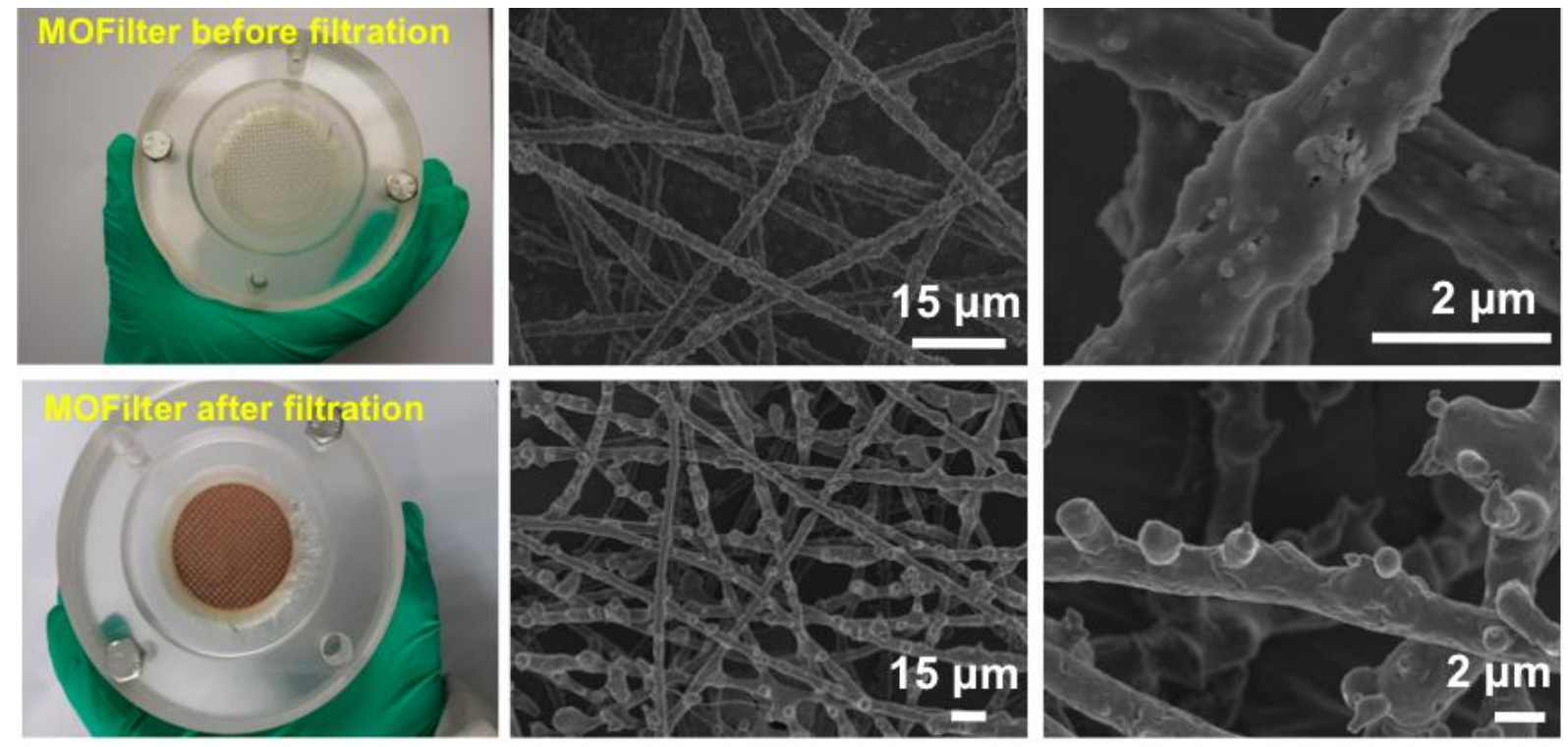

Figure S14. Photos and SEM images of the UiO-66- $\mathrm{NH}_{2} / \mathrm{PAN}$ MOFilter (60 wt $\%$ loading) before and after smoke capture. 


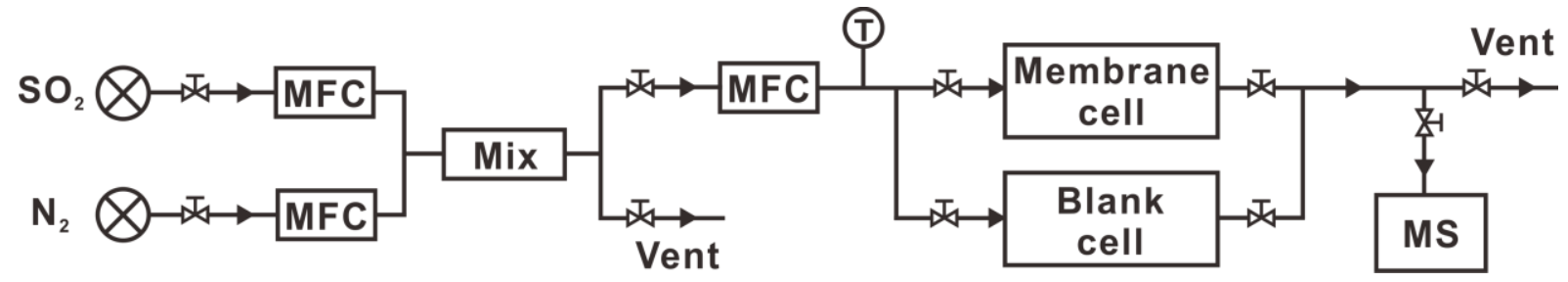

Figure S15. Schematic of the apparatus for $\mathrm{SO}_{2}$ dynamic adsorption tests. 

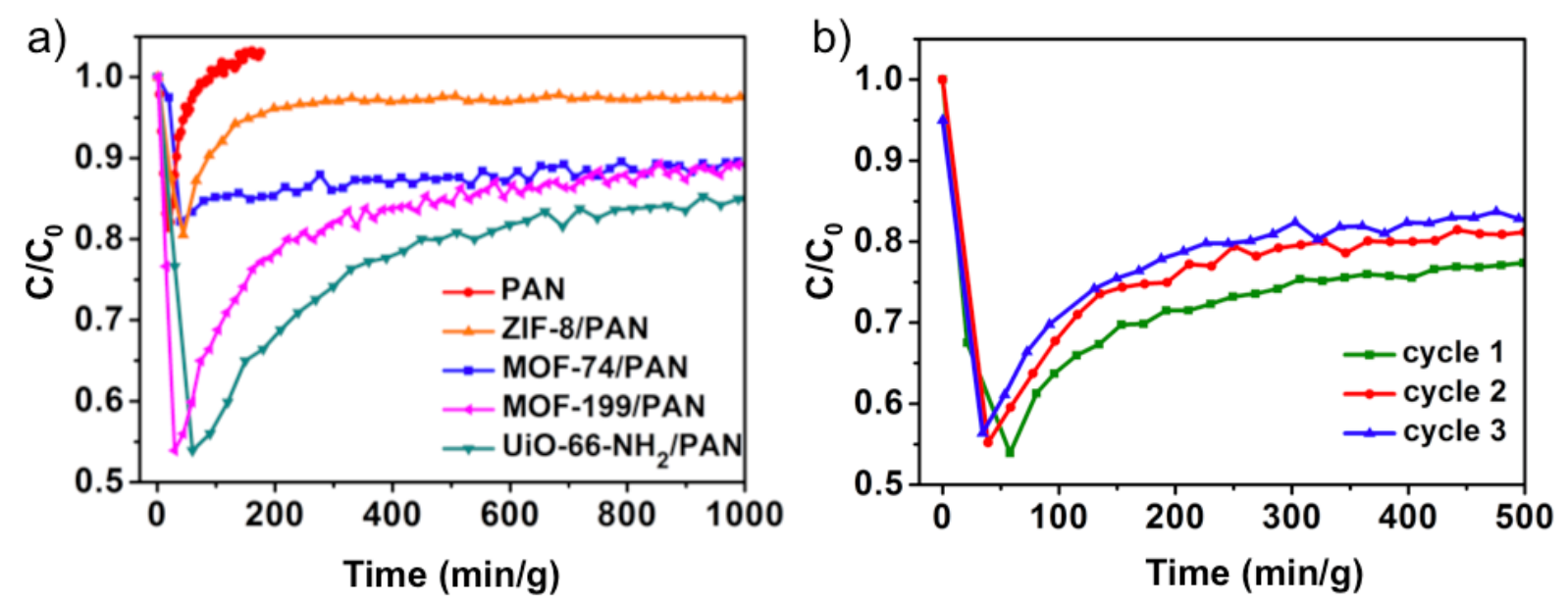

Figure S16. (a) Kinetic breakthrough curves of $\mathrm{SO}_{2}$ for PAN filter and PAN-MOFilters at 25 ${ }^{\circ} \mathrm{C}$ with a $100 \mathrm{ppm} \mathrm{SO} \mathrm{SO}_{2} / \mathrm{N}_{2}$ flow at the rate of $50 \mathrm{~mL} / \mathrm{min}$. (b) Cycle performance of UiO-66- $\mathrm{NH}_{2} / \mathrm{PAN}$ MOFilter after regenerating with a $\mathrm{N}_{2}$ flow rate of $50 \mathrm{~mL} / \mathrm{min}$ at $25^{\circ} \mathrm{C}$. 


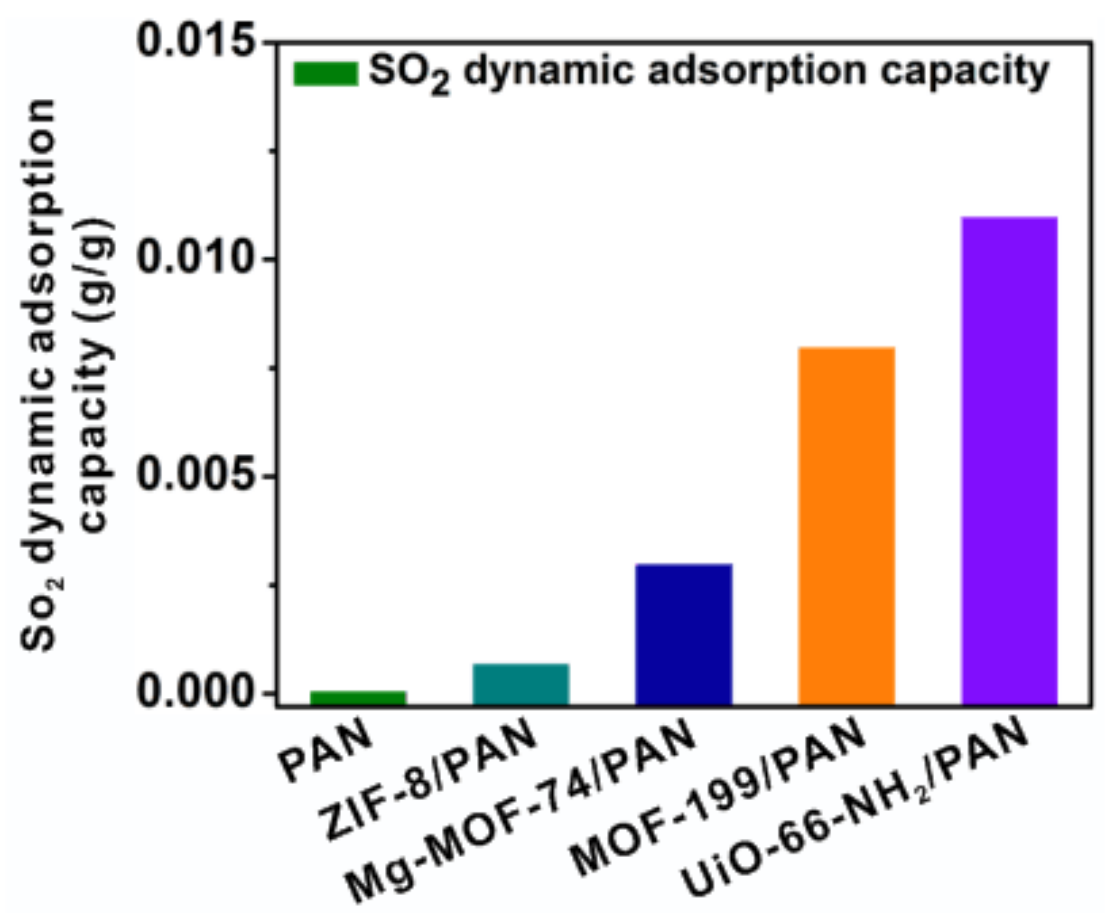

Figure S17. $\mathrm{SO}_{2}$ dynamic adsorption of humidified PAN filter and PAN-MOFilters at $25^{\circ} \mathrm{C}$ with a $100 \mathrm{ppm} \mathrm{SO} / \mathrm{N}_{2}$ flow at the rate of $50 \mathrm{~mL} / \mathrm{min}$. The filters were humidified in air at the relative humidity of $60 \%$ before test. 

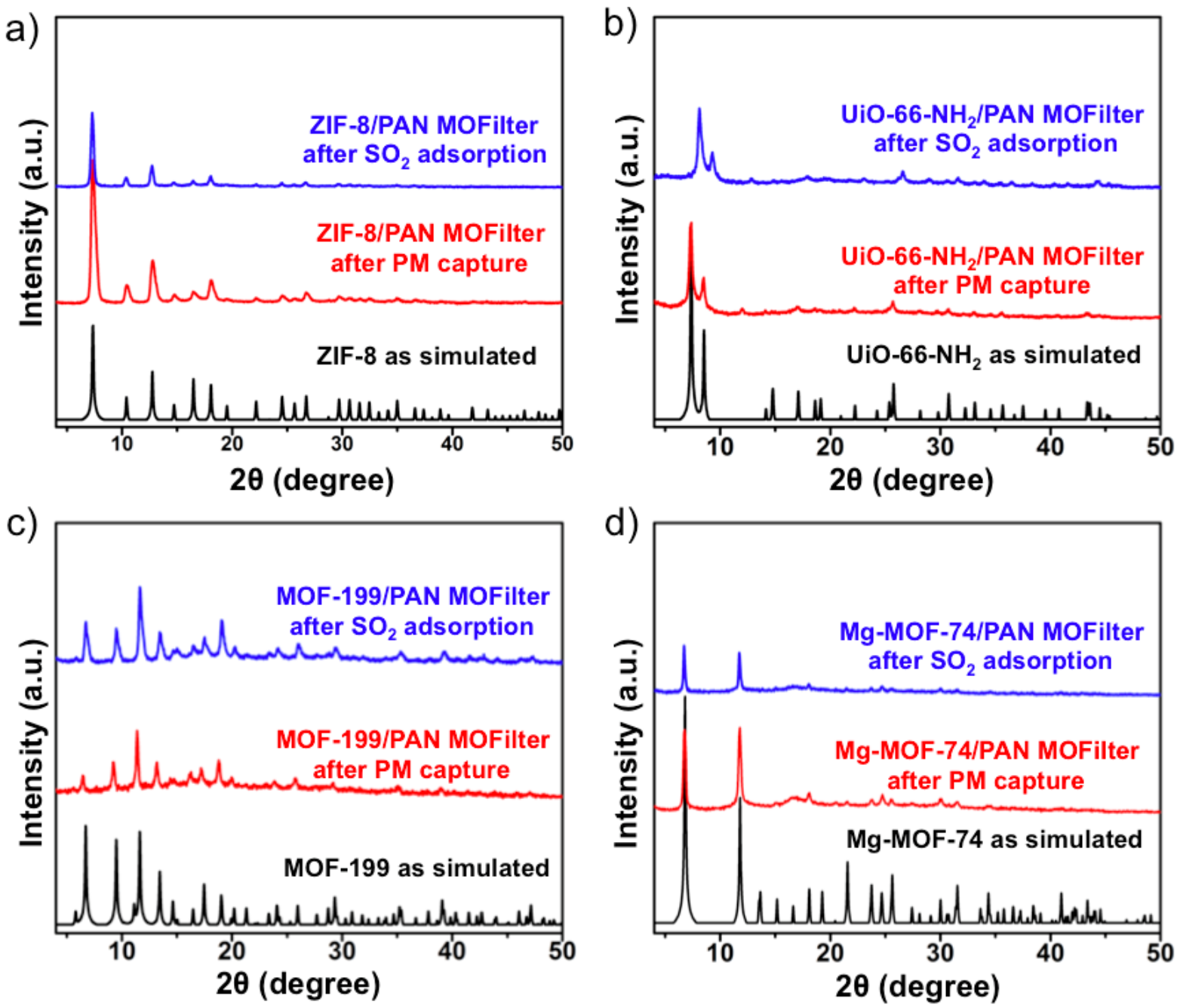

Figure S18. PXRD patterns of (a) ZIF-8/PAN MOFilter, (b) UiO-66- $\mathrm{NH}_{2} / \mathrm{PAN}$ MOFilter, (c) MOF-199/PAN MOFilter and (d) Mg-MOF-74/PAN MOFilter after PM capture and $\mathrm{SO}_{2}$ adsorption. All the filters were tested without substrate. 


\section{Section D. Supporting references}

(1) Katz, M. J.; Brown, Z. J.; Colón, Y. J.; Siu, P. W.; Scheidt, K. A.; Snurr, R. Q.; Hupp, J. T.; Farha, O. K. Chem. Commun. 2013, 49, 9449.

(2) Cravillon, J.; Nayuk, R.; Springer, S.; Feldhoff, A.; Huber, K.; Wiebcke, M. Chem. Mater. 2011, 23, 2130.

(3) Britt, D.; Furukawa, H.; Wang, B.; Glover, T. G.; Yaghi, O. M. Proc. Natl. Acad. Sci. U. S. A. 2009, 106, 20637.

(4) Choi, K. M.; Jeong, H. M.; Park, J. H.; Zhang, Y.-B.; Kang, J. K.; Yaghi, O. M. ACS Nano 2014, 8, 7451 . 